\title{
The knowledge mobilisation challenge: does producing evidence lead to its adoption within dentistry?
}

\author{
T. L. Goodwin, ${ }^{* 1}$ P. R. Brocklehurst ${ }^{2}$ and L. Williams ${ }^{3}$
}

\section{In brief}

Demonstrates that producing evidence in dentistry does not automatically translate into it being adopted or sustained within a clinical setting.
Provides an explanation as to why this process is not automatic.
Discusses how the use of human intermediaries and communities of practice could be used to overcome this hurdle.

The transfer of evidence into clinical practice is the ultimate aim of those engaged in health research. But is this a process that occurs naturally? Can health researchers take it for granted that the evidence they produce will be embraced by clinicians and incorporated into their everyday practice? In this article, we use the example of oral healthcare in dependent older people and the issue of antibiotic prescribing by GDPs to illustrate the fact that successful knowledge transfer between researchers and practitioners cannot be automatically assumed. What is needed, so we argue, are certain tools to facilitate the knowledge transfer, exchange and implementation process. These tools may take the form of human intermediaries, who can occupy the space in between the worlds of research and practice, acting as brokers to mobilise knowledge, or through the establishment of communities of practice. We outline both of these approaches here as a potential solution to the problem of knowledge mobilisation in dentistry.

\section{Care in older people}

Dental caries in older populations is a major public health issue ${ }^{1-3}$ with $40 \%$ of those aged between 75 and 84 affected. ${ }^{4}$ Older people living in care homes - or who are looked after at home - are at a particular risk here due to high levels of dependency and dementia. ${ }^{5}$ The problem is compounded by the fact that they frequently rely on care home staff or carers to help maintain their oral health. This requires these staff and carers to understand both the importance of oral health and how to deliver this aspect of personal care effectively and confidently to the people they look after. The structural context in which oral health improvement is delivered also presents challenges. Although, since April 2013, local

'The University of Manchester, Division of Dentistry, The University of Manchester, Manchester, M13 9PL; ${ }^{2}$ Director of NWORTH Clinical Trials Unit and Honorary Consultant in Dental Public Health; ${ }^{3}$ School of Healthcare Sciences, Bangor University Holyhead Road, Gwynedd, LL57 2PZ ${ }^{*}$ Correspondence to: Tom Goodwin

EmailL tom.goodwin@manchester.ac.uk

Refereed Paper. Accepted 25 October 2017

DOI: $10.1038 /$ sj.bdj.2018.45 authorities have the statutory responsibility for oral health improvement, there are a number of organisations/providers now involved including: NHS England, Health Education England, Clinical Commissioning Groups, the voluntary and community sector, community NHS services as well as independent dental practices that are subcontracted to deliver NHS dental services. This requires coordinated action across these various stakeholders. Although presented by the coalition government as a simplifying measure, the health and social care reforms that were introduced post April 2013 have in practice, as Nicholas Timmons from the King's Fund argues, 'spawned an at times bewildering array of often non-statutory bodies, all of which are expected to have some say and influence. ${ }^{6}$

With a view to addressing these complexities, guidelines produced by both the National Institute for Health and Care Excellence $(\mathrm{NICE})^{7}$ and NHS Health Scotland ${ }^{8}$ address the issues of oral healthcare for dependent older people by providing an array of knowledge and guidance on the kinds of practical skills and expertise required to facilitate better oral health in this population group. This is due to be supplemented by the imminent publication of a toolkit produced by Public Health England ${ }^{9}$ which will provide a review of the current literature and guidance, links to relevant tools and resources, as well as advice for local authority public health teams on navigating the post-April 2013 landscape.

Nevertheless, the provision of dental care for dependent older people remains highly variable. In Greater Manchester, for example, a recent survey of care service managers revealed that over half of 'care in your home' and residential care services do not have a policy in place to support daily oral care for their clients, and, that over a quarter did not train their staff on when and how to obtain urgent dental treatment. ${ }^{10}$ Similarly, a recent Healthwatch survey in Bolton found that half of residential care homes did not have arrangements in place to access routine or emergency care for their residents and 8\% of them had resorted to taking a resident to a hospital accident and emergency department because of dental problems. ${ }^{11}$

In other words, despite the existence of knowledge which aims to promote better oral health in dependent older people, this 
information is not being translated into upto-date clinical practice. The reasons for this schism are multifactorial.

First, the implementation chain here is highly complex, with the literature citing a number of potential challenges to the implementation of oral health promotion interventions within care homes. ${ }^{8}$ These relate to the following:

- This aspect of care is considered by some carers as distasteful

- There may be confusion over consent issues, fear of personal harm from resistant residents, or a lack of dementia-specific care skills that can discourage care staff from carrying out oral care

- Care staff (and managers) may not give oral care tasks the priority that other care tasks receive.

Second, a number of the studies that support the effectiveness of the interventions that are promoted in the guidelines have not been conducted in UK nations. For example, with respect to the promotion of training programmes in oral health for care staff and carers, the majority of the studies demonstrating effectiveness are from Europe and North America. As such, while this may be sufficient to demonstrate effectiveness per se, it provides no insight as to how the peculiarities of the implementation chain in UK nations may affect knowledge transfer and exchange in this different setting.

Third, and perhaps most crucially, the emerging consensus from within the field of implementation science is that conventional linear models of knowledge transfer - where evidence is pushed from its producers toward potential users or vice versa - does not successfully move potentially useful research findings into practice. ${ }^{12,13}$ As Jonathan Lomas, chief executive officer of the Canadian Health Services Research Foundation argues, ${ }^{12}$ 'the inner workings, implicit rules, cultures, and realities that dominate the day to day lives of people working in the health system and those doing research on that system remain, for the most part, mysteries to people on the other side.' A particular challenge to integrating evidence into practice is that it requires the acquisition and conversion of both explicit and tacit knowledge into practical activities. Codified information in the form of peerreviewed journals, rules and guidelines needs to be digested by practitioners and made sense of in the context in which it is to be used. ${ }^{14} \mathrm{We}$ return to this crucial point later in the article.

\section{Antibiotic prescribing}

Resistance to antibiotics is a growing threat to global public health and patient safety, resulting in increased morbidity and mortality. ${ }^{15,16}$ Increased use of antibiotics is a major contributor to the spread of anti-microbial resistance, ${ }^{17,18}$ with dentists bearing responsibility for approximately $10 \%$ of all antibiotics dispensed in UK community pharmacies. ${ }^{19-22}$

Clinical guidance advising on the optimal use of antibiotics is clear and seeks to improve the quality of care provided to patients by decreasing inappropriate prescription. ${ }^{23,24}$ However, evidence shows that dentists often prescribe antibiotics inappropriately in the absence of clinical need. ${ }^{19,21,25,26}$ For example, antibiotics are used to treat inflammatory conditions such as irreversible pulpitis and as a substitute to performing operative treatment in emergency dental clinics. ${ }^{19}$

In response to the issue of antibiotic prescribing, the Translation Research in a Dental Setting (TRiaDS) programme, based in Scotland, has recently trialled an audit and feedback (A\&F) intervention to encourage dentists to follow guidelines. This intervention measures their professional practice and performance and compares it to the appropriate standards and targets. In other words, it provides an 'audit' of the GDP's performance. The results of this comparison are then fed-back to the individual, in order to draw their attention to any discrepancy, with a view to them modifying their behaviour if required. ${ }^{27}$

After receiving the $A \& F$ intervention, the rate of antibiotic prescribing by GDPs was reduced from 8.5 items per $100 \mathrm{NHS}$ treatment claims, at baseline, to 7.5 items per $100 \mathrm{NHS}$ treatment claims at follow-up. GDPs in the control group also reduced antibiotic prescribing from 8.3 items per $100 \mathrm{NHS}$ treatment claims to 7.9 items per 100 NHS treatment claims, giving an overall adjusted effect size of 0.47 ( $95 \%$ CI 0.09 to 0.85 ) fewer antibiotic items per 100 NHS treatment claims. The primary analysis revealed this to be a significant change $(\mathrm{P}=0.01)$, representing a $5.7 \%$ reduction ( $95 \% \mathrm{CI}-1.1 \%$ to $-10.2 \%$ ) in the antibiotic prescribing rate in the intervention group relative to the control group. ${ }^{27}$

However, although these results highlight a statistical significance regarding the intervention's effectiveness, how significant are they in a broader context? Some policy-makers would probably like to see a more significant change in behaviour; greater than one item per 100 for example.
In addition, as the authors of the $\mathrm{A} \& \mathrm{~F}$ study point out, the trial does have certain limitations: namely, the relatively short duration of the follow-up (nine months); as well as the fact that they did not evaluate the impact of the intervention on the quality or appropriateness of GDPs' antibiotic prescribing. Furthermore, there is currently no funding to enable continued delivery of the intervention. As such, this raises the following problems.

First, given the fact that there was no broader evaluation looking at quality or appropriateness, the mechanisms of action here remain obscured. Simply put, we don't know why GDPs prescribed less after receiving the A\&F intervention. Was it because they suddenly became aware of what the guideline said they should do? Or, were they already aware but failed to adhere to it until they were being monitored? In short, we just don't know.

Second, even if we had more insight as to why GDPs prescribed less after receiving A\&F there is still a vulnerability here. The problem with this kind of behaviour change intervention is that there appears to be an element of 'nudging. The basic premise is that your clinical behaviour is audited and discrepancies are highlighted which nudges you in the direction of the appropriate practice. However, nudging people in one direction may leave them vulnerable to being nudged back again, ${ }^{28}$ especially in this context where there is currently no funding to enable continued delivery of the intervention and thereby maintain its impact. Once the pressure imposed by the A\&F recedes, GDPs may simply return to their old habits.

In light of this vulnerability: are there more effective ways of ensuring the successful transfer of knowledge from research into practice?

\section{Facilitating knowledge transfer}

The emerging view from the knowledge mobilisation and implementation science literature is that connecting research evidence to practice should be as much a social exercise, involving interpersonal networks and social interaction, as a technical one involving clinical guidelines and performance indicators. ${ }^{29,30}$ The sense behind this imperative can be illustrated by considering in more detail what affects successful knowledge transfer in relation to guideline adherence. Even if GDPs are familiar with a particular guideline, if their personal interpretation of the evidence differs from that of the guideline developers, or if they simply 
disagree with its content, this can severely limit its implementation. ${ }^{19}$ For example, a recent qualitative study examining views on the NICE guidelines for antibiotic prophylaxis highlighted reservations by a number of GDPs in relation to the evidence base. ${ }^{31}$ Inertia of previous practice, as well as structural issues, can also have an effect. A qualitative study of a collaborative clinical audit revealed that the isolation some GDPs feel in their practice environment can affect awareness of guidelines per se, as well as attitudes to change. ${ }^{32}$

More broadly, as mentioned above, a particular challenge to integrating evidence into practice is that it requires the acquisition and conversion of both explicit and tacit knowledge into practical activities. As noted, the kind of codified information found within guidelines needs to be digested by practitioners and made sense of in the context in which it is to be used. ${ }^{14}$

As we have therefore argued elsewhere, ${ }^{5}$ successful knowledge transfer is contingent on the complex interplay of the evidence to be implemented: how robust it is and how it fits with local experience; the local context in which implementation is to take place (the prevailing culture, leadership, and commitment to evaluation and learning); and the way in which the process is facilitated (how and by whom). ${ }^{33-36}$ Rather than relying on simple behavioural change interventions, our contention is that there are potentially more effective ways of facilitating successful knowledge transfer: namely through the use of both communities of practice and human intermediaries.

Communities of Practice (CoPs) are described as 'groups of people who share a concern, a set of problems, or a passion about a topic, and who deepen their knowledge and expertise in this area by interacting on an on-going basis. ${ }^{37}$ The idea is that meaning and context can be attributed to codified information by discussion with colleagues and mentors or by observing how others apply knowledge and then trying it for themselves. It is argued that CoPs help to nurture and harness knowledge, particularly the facilitation and exchange of tacit knowledge. They are said to drive innovation and help individuals and organisations improve practice and performance. CoPs can range in size and location, they can be homogeneous or heterogeneous, spontaneous or intentional, unrecognised or institutionalised. ${ }^{38}$ Hence, they are being used in increasing numbers in the health care field with a view facilitating knowledge transfer and exchange. ${ }^{39}$

Intermediaries, who are also known as champions, change agents, facilitators, opinion leaders and linking agents, are individuals within a clinical environment who can influence other practitioners towards best practice. ${ }^{40}$ Using both clinical judgement and knowledge of research, they are able to bridge the gap between theory and practice in a clinical setting ${ }^{41}$ and have been found to be effective mobilisers of research use in practice. ${ }^{42-44}$ Evidence from a recent mixed methods study in infection prevention suggests their effectiveness is linked to several mechanisms of action, such as: the presence of and surveillance by the intermediaries in clinical areas; ways of giving feedback; increased attention to their being seen in practice; bringing education into the workplace; and building trust into relationships. ${ }^{40}$

We believe that the use of both CoPs and human intermediaries could be successfully applied within dentistry to help solve the knowledge mobilisation problems that we've raised above.

CoPs in particular, and especially online CoPs (VCoPs), could provide a means of assisting knowledge mobilisation among GDPs in their practice environment. The use of a web-based knowledge and exchange environment could provide geographically dispersed clinicians with the means to network and communicate more frequently, reducing professional isolation, and promoting knowledge transfer and exchange activities. The literature suggests that VCoPs can be an effective tool in this context, enabling geographically dispersed practitioners to gather and share information. ${ }^{45,46}$

Human intermediaries have the potential to be effective, particularly in a care home setting and as a tool for promoting better oral health in dependent older people. A recent pilot study ${ }^{47}$ established the feasibility of a training and knowledge transfer programme in a residential aged care facility. It found that trained lead advocate nurses could carry out multifactor risk assessments on early dementia patients and select appropriate preventive interventions. It also found that the nurses could implement their care plans, monitoring compliance and transferring knowledge to the wider untrained nursing team. More widespread usage of this approach could therefore be a fruitful approach to knowledge transfer and exchange in a care home setting.

\section{Conclusion}

Our purpose in this paper has been to highlight the challenge of knowledge mobilisation within a dental setting and to establish that knowledge transfer and exchange cannot be taken for granted. Having suggested that certain tools are required to facilitate the knowledge mobilisation process, a comprehensive evaluation of these techniques is now required to establish their effectiveness.

1. Murray Thomson W. Epidemiology of oral health conditions in older people. Gerodontology 2014; 31(suppl. 1): 9-16.

2. Karki A J, Monaghan N, Morgan M. Oral health status of older people living in care homes in Wales. Br Dent $J$ 2015; 219: 331

3. Morgan M Z, Johnson I G, Hitchings E, Monaghan N P, Karki A J. Dentist skill and setting to address dental treatment needs of care home residents in Wales. Gerodontology 2016; 33: 461-469.

4. White D, Pitts N, Steele J, Sadler K, Chadwick B L. Disease and related disorders-a report from the Adult Dental Health Survey 2009. Available online at http://digital.nhs.uk/media/16627/Adult-DentalHealth-Survey-England-Wales-Northern-Ireland2009-Theme-2-Disease-Related-Disorders/Any/ adul-dent-heal-surv-summ-them-the2-2009-rep4 (accessed January 2018).

5. Brocklehurst $\mathrm{P}$, Williams L, Hoare Z et al. Strategies to prevent oral disease in dependent older people. Cochrane Database Syst Rev 2016; DOI: 10.1002/14651858.CD012402.

6. Timmins N. The four UK health systems: learning from each other. King's Fund; 2013. Available at https://www. kingsfund.org.uk/sites/default/files/field/field_publication_summary/four-uk-health-systems-jun13.pdf (accessed January 2018).

7. National Institute for Health and Care Excellence. Oral health for adults in care homes Guidance and guidelines - NICE [PHG62]. NICE; 2016. Available at https://www. nice.org.uk/guidance/ng48 (accessed January 2018).

8. NHS Health Scotland. Caring for Smiles Guide for Care Homes. 2013. Available at http://www.nes.scot.nhs.uk/ media/2603965/caring_for_smiles_guide_for_care_ homes.pdf (accessed January 2018).

9. Public Health England. Commissioning better oral health for vulnerable older people An evidence-informed toolkit for local authorities [Draft]. In press. Expected publication in 2018 and will be made available via: https:// www.gov.uk/government/publications?departments[]=p ublic-health-england.

10. Public Health England. Report 1: 'Care in your home'. Dental public health intelligence programme North West oral health survey of services for dependant older people, 2012 to 2013. 2013. Available at http://www.nwph. net/dentalhealth/Care $\% 20$ in $\% 20$ your $\% 20$ home $\% 20$ report\%202013.pdf (accessed January 2018).

11. Healthwatch Bolton, Healthwatch Kirklees. Oral health in care homes. Evidence from Bolton and Kirklees. 2014. Available at http://healthwatchbolton.co.uk/wp-content/ plugins/download-attachments/includes/download. php?id=1088 (accessed January 2018).

12. Lomas J. The in-between world of knowledge brokering BMJ 2007; 334: 129-132.

13. Marshall M, Pagel C, French C et al. Moving improvement research closer to practice: the Researcher-in-Residence model. BMJ Qual Saf 2014; 23: 801-805.

14. Li L C, Grimshaw J M, Nielsen C, Judd M, Coyte P C, Gra ham I D. Evolution of Wenger's concept of community of practice. Implement Sci 2009; 4: 11

15. Goossens H, Ferech M, Vander Stichele R, Elseviers $M$, ESAC Project Group. Outpatient antibiotic use in Europe and association with resistance: a cross-national database study. Lancet 2005; 365: 579-587.

16. World Health Organisation. Antimicrobial resistance: global report on surveillance. 2014. Available at http:// 
www.who.int/drugresistance/documents/surveillancereport/en/ (accessed January 2018).

17. Wilcox M H. The tide of antimicrobial resistance and selection. Int J Antimicrob Agents 2009; 34: S6-S10.

18. Martin M V. Antimicrobials and dentistry: a rationale for their use. Fac Dent J 2010; 1: 15-19.

19. Cope A L, Chestnutt I G. Inappropriate prescribing of antibiotics in primary dental care: reasons and resolutions. Prim Dent J 2014; 3: 33-37.

20. Scottish Antimicrobial Prescribing Group (SAPG). Primary Care Prescribing Indicators Annual Report 2013/14. 2014. Available at https://www.scottishmedicines.org. uk/files/sapg/2014-10-14-SAPG-Primary-Care-PI-201314-Report.pdf (accessed January 2018).

21. Johnson T M, Hawkes J. Awareness of antibiotic prescribing and resistance in primary dental care. Prim Dent J 2014; 3: 44-47.

22. Health and Social Care Improvement Centre. Prescribing by dentists. 2014. Available at http://content.digital.nhs. uk/catalogue/PUB17425/pres_dent_eng_2014_rep.pdf (accessed January 2018).

23. Scottish Dental Clinical Effectiveness Programme SDcep. Drug Prescribing For Dentistry Dental Clinical Guidance. 2016. Available at http://www.sdcep.org.uk/ wp-content/uploads/2016/03/SDCEP-Drug-Prescribing for-Dentistry-3rd-edition.pdf (accessed January 2018).

24. Palmer N O, Longman L, Randall C, Pankhurst C L. Antimicrobial prescribing for general dental practitioners. Faculty of General Dental Practitioners (FGDP), UK 2014.

25. Dar-Odeh N S, Abu-Hammad O A, Al-Omiri M K, Khraisat A S, Shehabi A A. Antibiotic prescribing practices by dentists: a review. Ther Clin Risk Manag 2010; 6: 301.

26. Dailey $Y$, Martin M. Are antibiotics being used appropriately for emergency dental treatment? Br Dent J 2001; 191: 391.
27. Elouafkaoui P, Young L, Newlands R et al. An audit and feedback intervention for reducing antibiotic prescribing in general dental practice: The RAPiD cluster randomised controlled trial. PLoS Med 2016; 13: e1002115.

28. Goodwin T L. Why we should reject 'nudge'. Politics 2012; 32: 85-92.

29. Greenhalgh T, Robert G, Macfarlane F, Bate P, Kyriakidou 0 . Diffusion of innovations in service organizations: systematic review and recommendations. Milbank $Q$ 2004; 82: 581-629.

30. Gabbay J, le May A. Evidence based guidelines or collectively constructed 'mindlines?' Ethnographic study of knowledge management in primary care. BMJ 2004; 329: 1013.

31. Soheilipour S, Scambler S, Dickinson C et al. Antibiotic prophylaxis in dentistry: part I. A qualitative study of professionals' views on the NICE guideline. Br Dent $J$ 2011; 211: E1.

32. Palmer N A, Dailey Y M. General dental practitioners' experiences of a collaborative clinical audit on antibiotic prescribing: a qualitative study. Br Dent J 2002; 193: 46.

33. Brocklehurst $P R$, Williams $L$, Burton $C$, Goodwin $T L$, Rycroft-Malone J. Implementation and trial evidence: a plea for fore-thought. Br Dent J 2017; 222: 331-335.

34. Kitson A, Harvey G, McCormack B. Enabling the implementation of evidence based practice: a conceptual framework. Qual Safety Health Care 1998; 7: 149-158.

35. Rycroft-Malone J. The PARIHS framework - A framework for guiding the implementation of evidence-based practice. J Nurs Care Qual 2004; 19: 297-304.

36. Straus S E, Tetroe J, Graham I. Defining knowledge translation. CMAJ 2009; 181: 165-168.

37. Wenger E, McDermott R A, Snyder W. Cultivating communities of practice: A guide to managing knowledge. Harvard Business Press; 2002.
38. Kislov R, Harvey G, Walshe K. Collaborations for Leadership in Applied Health Research and Care: lessons from the theory of communities of practice. Implement $\mathrm{Sci}$ 2011; 6: 64.

39. Li L C, Grimshaw J M, Nielsen C, Judd M, Coyte P C, Graham I D. Use of communities of practice in business and health care sectors: a systematic review. Implement Sci 2009; 4: 27.

40. Williams L, Burton C, Rycroft-Malone J. What works: a realist evaluation case study of intermediaries in infection control practice. J Adv Nurs 2013; 69: 915-926.

41. Ferguson L, Milner M, Snelgrove-Clarke E. The role of intermediaries: getting evidence into practice. J Wound Ostomy Continence Nurs 2004; 31: 325-327.

42. Dopson S, FitzGerald L, Ferlie E, Gabbay J, Locock L. No magic targets! Changing clinical practice to become more evidence based. Health Care Manage Rev 2002; 27: 35-47.

43. McCaughan D, Thompson C, Cullum N, Sheldon T A, Thompson D R. Acute care nurses' perceptions of barriers to using research information in clinical decisionmaking. J Adv Nurs 2002; 39: 46-60.

44. Thompson G N, Estabrooks C A, Degner L F. Clarifying the concepts in knowledge transfer: a literature review J Adv Nurs 2006; 53: 691-701.

45. Curran J A, Murphy A L, Abidi S S, Sinclair D, McGrath P J. Bridging the gap: knowledge seeking and sharing in a virtual community of emergency practice. Eval Health Prof 2009; 32: 314-327.

46. Thomas A U, Fried G P, Johnson P, Stilwell B J. Sharing best practices through online communities of practice: case study. Hum Resour Health 2010; 8: 25.

47. Deutsch A, Siegel E, Cations M, Wright C, Naganathan $\checkmark$, Brodaty H. A pilot study on the feasibility of training nurses to formulate multicomponent oral health interventions in a residential aged care facility. Gerodontology 2017; 34: 469-478. 